\title{
Towards a Framework to Support the Design of Esports Curricula in Higher Education
}

\author{
Michael James Scott* \\ michael.scott@falmouth.ac.uk \\ Falmouth University \\ Cornwall, United Kingdom \\ Cornelia Connolly \\ cornelia.connolly@nuigalway.ie \\ National University of Ireland, \\ Galway, Ireland \\ Seth Jenny \\ seth.jenny@sru.edu \\ Slippery Rock University \\ PA, United States
}

\author{
Rory Summerley* \\ r.summerley@falmouth.ac.uk \\ Falmouth University \\ Cornwall, United Kingdom \\ Joey Gawrysiak \\ jgawrysi@su.edu \\ Shenandoah University \\ VA, United States \\ Michael Miljanovic \\ mike.miljanovic@utoronto.ca \\ University of Toronto \\ Canada
}

\author{
Nicolas Besombes \\ nicolas.besombes@u-paris.fr \\ University of Paris \\ France \\ Tzipora Halevi \\ halevi@sci.brooklyn.cuny.edu \\ City University of New York \\ NY, United States \\ Melissa Stange \\ mstange@lfcc.edu \\ Lord Fairfax Community College \\ VA, United States
}

\author{
Toni Taipalus \\ toni.taipalus@jyu.fi \\ University of Jyvaskyla \\ Finland
}

\author{
J. Patrick Williams \\ patrick.williams@ntu.edu.sg \\ Nanyang Technological University \\ Singapore
}

\begin{abstract}
Esports has generated an industry of increasing economic and cultural importance. In recent years, universities and other higher education institutions have responded to its growth by establishing undergraduate courses to satisfy the needs of innovators operating in the area. However, there is not yet consensus on what an esports curriculum should include. Despite being a technology-driven sector with ethical and professional dimensions that intersect computing, current ACM and IEEE curricula do not mention esports. Furthermore, existing courses tend to provide teaching and training on a wide variety of topics aside from those traditionally in computer science. These include: live events management; psychological research; sports science; marketing; public relations; video (livestream) production; and community management; in addition to coaching. This working group seeks to examine the requirements for developing esports studies at universities with a focus on understanding career prospects in esports and on the challenges presented by its disciplinary complexity. The group will identify key learning outcomes and assess how they align with industry needs, paving the way for a framework to support the design of esports curricula in higher education.
\end{abstract}

*(co-leaders)

Permission to make digital or hard copies of part or all of this work for personal or classroom use is granted without fee provided that copies are not made or distributed for profit or commercial advantage and that copies bear this notice and the full citation on the first page. Copyrights for third-party components of this work must be honored. For all other uses, contact the owner/author(s).

ITiCSE 2021, June 26-fuly 1, 2021, Virtual Event, Germany

(C) 2021 Copyright held by the owner/author(s).

ACM ISBN 978-1-4503-8397-4/21/06.

https://doi.org/10.1145/3456565.3461440

\section{CCS CONCEPTS}

- Social and professional topics $\rightarrow$ Computing education programs; Computing industry; Model curricula.

\section{KEYWORDS}

esports, curriculum, course design, higher education, e-sports, eSports, electronic sports, vsports, v-sports, vSports, virtual sports, cybersports, eGames, e-games, e-gaming, professional gaming

\section{ACM Reference Format:}

Michael James Scott, Rory Summerley, Nicolas Besombes, Cornelia Connolly, Joey Gawrysiak, Tzipora Halevi, Seth Jenny, Michael Miljanovic, Melissa Stange, Toni Taipalus, and J. Patrick Williams. 2021. Towards a Framework to Support the Design of Esports Curricula in Higher Education. In 26th ACM Conference on Innovation and Technology in Computer Science Education V. 2 (ITiCSE 2021), fune 26-fuly 1, 2021, Virtual Event, Germany. ACM, New York, NY, USA, 2 pages. https://doi.org/10.1145/3456565.3461440

\section{BACKGROUND \& MOTIVATION}

The esports industry is emerging as a global phenomenon of significant and increasing importance, both economic and cultural. Though esports has existed since at least the late 1990s [20], as platforms, infrastructure, and multimedia streaming have matured, it has become increasingly democratised [17] meaning it has become more accessible to members of the public. As such, in recent years the sector has been booming [10], with audiences reaching 495 million people in the early months of 2020 [15]. Ahn, Collis and Jenny [1] showed that global esports revenues surpassed $\$ 24.9$ billion in 2019, and it is anticipated that esports viewership will continue to grow following increased public awareness in the wake of the COVID-19 pandemic [8]. 
With this being the case, the scale of the industry is driving educators to consider the knowledge, skills, and attitudes that will be relevant to this new sector. Esports is appearing in many higher education institutions across the world [13], often in different ways and in different contexts [5]. Likewise, many students already spectate or participate in esports, expressing interests in the career opportunities that it presents. However, there does not seem to be a widespread understanding of career prospects amongst university educators. The novelty and nuances of the industry make such considerations a non-trivial endeavour.

Setting aside debates on what esports is or isn't (e.g., $[4,6,19])$ and on varying terminology (from [6]: electronic sports; cybersports; professional gaming; competitive computer gaming; and virtual sports), there isn't yet a widely accepted notion of what esports professionals do. For the most part, people in the industry are involved in a form of media creation and consumption which surrounds an activity which is similar, in at least some ways, to that of traditional sports. Some recent work places emphasis on livestreaming [7]: content that is produced, recorded, and broadcast online in real-time. This may be due to the appeal of live interaction with such broadcasts and the increasing popularity of Twitch and YouTube. However, different parts of the industry focus on different aspects of this process and at differing scales. So, although it is at least clear that a media and entertainment industry has emerged to support the spectatorship of esports, its spheres of activity are diverse and draw upon skills across a wide range of domains.

In line with these debates and this broadness, calls to action argue that commercial activities in this sector are not "studied in an adequate degree" [11]. This raises the question: what should an esports curriculum include? The disciplinary entanglement inherent to esports problematises traditional degree pathways. Anderson et al. argue that esports "connects to STEM entrepreneurship, and [forms] a community that natively fosters acquisition and mastery of knowledge and skills that connect to high tech sector jobs" [2]. Computing educators will, therefore, have a key role to play in the design and delivery of esports education. However, whilst there is promising work on transferable skills [9], there is a conspicuous absence of discourse on esports itself in the computing education literature. It doesn't receive a mention in CC2020 [16] and would be a timely inclusion into CS202X. Computing educators also have a role to play in nurturing critical thinking regarding esports. It faces many ethical and operational challenges $[12,14]$ which are relevant to computing professionals. Striving to preserve 'graduateness' in terms of reflective practice, scholarship, moral reasoning and lifelong learning (see [18]) would likely lead to critical engagement with such challenges. Thus, the state-of-the-art in esports would be driven towards a positive, equitable, and sustainable model.

In some ways this trend is reminiscent of the rise of game courses in higher education, with institutions using games as a means to attract and motivate students (e.g., [3]). However, the interface with computing departments will likely have greater complexity. Early adopters offer training and education that spans many areas aside from those traditionally in computing, such as: live events management; psychological research; sports science; marketing; public relations; video (livestream) production; and community management; in addition to coaching. As such career opportunities cross disciplinary boundaries to a greater extent than with games. Hence, a holistic lens is necessary.

This working group will therefore assemble a framework to help educators design curricula in this area by investigating the role of esports studies in higher education. This will focus on identifying learning outcomes whilst also assessing how they correspond to industry needs. It is anticipated such insight will not only aid educators in untangling the disciplinary complexity, but will also help curriculum designers wading into the esports domain. In doing so, this work will lay the foundations for future model esports curricula.

\section{REFERENCES}

[1] Joseph Ahn, William Collis, and Seth Jenny. 2020. The one billion dollar myth: Methods for sizing the massively undervalued esports revenue landscape. International Fournal of Esports 1, 1 (2020). https://www.ijesports.org/article/15

[2] Craig G Anderson, AM Tsaasan, Jason Reitman, Je Seok Lee, Minnie Wu, Holly Steel, Tom Turner, and Constance Steinkuehler. 2018. Understanding esports as a stem career ready curriculum in the wild. In 2018 10th International Conference on Virtual Worlds and Games for Serious Applications (VS-Games). IEEE, 1-6.

[3] Bill Clark, Jerry Rosenberg, Terrel Smith, Stu Steiner, Scott Wallace, and Genevieve Orr. 2007. Game development courses in the computer science curriculum. Fournal of Computing Sciences in Colleges 23, 2 (2007), 65-66.

[4] Juho Hamari and Max Sjöblom. 2017. What is eSports and why do people watch it? Internet research 27, 2 (2017), 211-232.

[5] Seth Jenny, Joey Gawrysiak, and Nicholas Besombes. forthcoming. Esports Academic Programming and Curricula: An Inventory and Analysis of Global Higher Education. (forthcoming). Unpublished manuscript.

[6] Seth E Jenny, R Douglas Manning, Margaret C Keiper, and Tracy W Olrich. 2017. Virtual(ly) athletes: where eSports fit within the definition of "Sport". Quest 69, 1 (2017), 1-18.

[7] Mark R Johnson and Jamie Woodcock. 2019. The impacts of live streaming and Twitch. tv on the video game industry. Media, Culture \& Society 41, 5 (2019), 670-688.

[8] Young Hoon Kim, John Nauright, and Chokechai Suveatwatanakul. 2020. The rise of E-Sports and potential for Post-COVID continued growth. Sport in Society 23, 11 (2020), 1861-1871. https://doi.org/10.1080/17430437.2020.1819695

[9] Je Seok Lee and Constance Steinkuehler. 2019. Esports as a catalyst for connected learning: the North America Scholastics Esports Federation. XRDS: Crossroads, The ACM Magazine for Students 25, 4 (2019), 54-59.

[10] Kevin Lehnert, Anna Walz, and Ryan Christianson. in press. The booming eSports market: a field day for fans. Journal of Business Strategy (in press). https://doi.org/10.1108/JBS-07-2020-0159

[11] Natalia Lokhman, Oksana Karashchuk, and Olena Kornilova. 2018. Analysis of eSports as a commercial activity. Problems and Perspectives in Management 16, 1 (2018), 207-213.

[12] Claudine McCarthy. 2019. Get an insider's glimpse into potential impact of esports. College Athletics and the Law 15, 12 (2019), 6-7.

[13] George S McClellan, Ryan S Arnett, and Charles M Hueber. 2020. Esports in Higher Education: Fostering Successful Student-Athletes and Successful Programs. Stylus Publishing, LLC, Sterling, VA.

[14] Stuart Murray, James Birt, and Scott Blakemore. in press. eSports diplomacy: towards a sustainable 'gold rush'. Sport in Society (in press), 1-19. https: //doi.org/10.1080/17430437.2020.1826437

[15] NewZoo. 2020. Newzoo Global Esports Market Report 2020. Retrieved Jan 5, 2021 from https://newzoo.com/insights/trend-reports/newzoo-global-esportsmarket-report-2020-light-version Commercial Report.

[16] ACM/IEEE Joint Task Force on Computing Curricula. 2020. Draft Report on Paradigms for Future Computing Curricula - Computing Curricula 2020. Retrieved Jan 5, 2021 from https://cc2020.nsparc.msstate.edu/wp-content/ uploads/2020/11/Computing-Curricula-Report.pdf Version 44, November 2020.

[17] Thomas Smith, Marianna Obrist, and Peter Wright. 2013. Live-Streaming Changes the (Video) Game. In Proceedings of the 11th European Conference on Interactive TV and Video (Como, Italy). ACM, New York, NY, 131-138.

[18] JM Steur, EPWA Jansen, and WHA Hofman. 2012. Graduateness: An empirical examination of the formative function of university education. Higher Education 64, 6 (2012), 861-874.

[19] Rory Summerley. 2020. The development of sports: A comparative analysis of the early institutionalization of traditional sports and e-sports. Games and Culture $15,1(2020), 51-72$.

[20] Michael G Wagner. 2006. On the Scientific Relevance of eSports.. In International Conference on Internet Computing. CSREA Press, 437-442. http://citeseerx.ist. psu.edu/viewdoc/download?doi=10.1.1.84.82\&rep=rep1\&type=pdf 